\title{
Compared with conventional procedures performed via the occipital horn, an intraoperative navigation system for ventriculoperitoneal shunting improves outcomes in patients with hydrocephalus
}

\author{
AiJun Peng \\ West China Hospital, Sichuan University \\ Hai Zhao \\ West China Hospital, Sichuan University \\ YongKang Wu \\ the Affiliated Hospital of Yangzhou University \\ Yi Zhao \\ the Affiliated Hospital of Yangzhou University \\ LiangXue Zhou ( $\nabla$ zhlxsch@163.com ) \\ West China Hospital of Sichuan University
}

\section{Research article}

Keywords: Hydrocephalus, Ventriculoperitoneal shunt, Intraoperative navigation, Ventricle catheter obstruction

Posted Date: June 19th, 2019

DOI: https://doi.org/10.21203/rs.2.10049/v3

License: (c) (i) This work is licensed under a Creative Commons Attribution 4.0 International License. Read Full License

Version of Record: A version of this preprint was published at British Journal of Neurosurgery on July 15 th, 2020. See the published version at https://doi.org/10.1080/02688697.2020.1789555. 


\section{Abstract}

Background: Ventriculoperitoneal shunting (VPS) is a common neurosurgical procedure used to treat hydrocephalus. Catheter obstruction is one of the most common factors that influences patient prognosis. We therefore evaluated the accuracy of proximal catheter placement and explored the probable relationship between ventricular catheter obstruction and both symptom grade and postoperative Evans index between an intraoperative navigation system for VPS and conventional surgery via the occipital horn. Methods: We performed a retrospective study of 33 patients with VPS (the navigation surgery group) and 26 patients with VPS (the conventional surgery group) seen between January 2012 and August 2018. The clinical data, follow-up times, catheterization accuracy, postoperative outcomes, cumulative survival times and correlations between catheter placement and obstruction, symptom grade and the postoperative Evans index were analyzed. Results: Thirty-one patients experienced optimal ventricular catheter placement (grade 1), 2 experienced suboptimal placement (grade 2), and none experienced poor ventricular catheter placement (grade 3) in the navigation surgery group, whereas 6, 14, and 6 patients, respectively, had these results in the conventional surgery group. Greater improvement was observed in postoperative symptoms $(P=0.017)$, including less catheter readjustment $(P<0.001)$, in the navigation surgery group. A Kaplan-Meier survival analysis showed that the cumulative catheter obstruction-free survival time was longer in the navigation surgery group than in the conventional surgery group $(\mathrm{P}=0.028)$. Moreover, catheter placement was significantly correlated with catheter obstruction $(\mathrm{P}<0.001)$. In addition, catheter obstruction was significantly correlated with the symptom grade $(P=0.001)$ and postoperative Evans index $(P<0.001)$. Conclusions: An intraoperative navigation system for VPS improved patient outcomes and the accuracy of ventricular catheter placement. Catheter obstruction-free survival times were longer in the navigation surgery group, and catheter placement was significantly correlated with catheter obstruction.

\section{Background}

Ventriculoperitoneal shunting (VPS) continues to be the most important surgical treatment for patients with hydrocephalus; these patients typically exhibit gait disturbance, cognitive impairment and urinary incontinence and show enlarged ventricles on computed tomography (CT) or magnetic resonance imaging (MRI). Previous studies[1-3] have reported that in patients with hydrocephalus who require cerebrospinal fluid (CSF) diversion, treatment can cost millions of dollars $[4,5]$ and therefore represents a significant burden to society.

Although patients with hydrocephalus significantly benefit from VPS, complications are unavoidable and influence the long-term survival of these patients. Some studies[6-9] have demonstrated that catheter obstruction may be the most common cause of shunt failure. Even experts who perform VPS according to cranial landmarks have certain misplacement rates. Proximal catheters with poor positioning are associated with a greater risk of catheter blockage[10, 11], which may require another surgery for catheter adjustment, causing additional suffering in the patient and contributing to increased financial and social burdens on families. Therefore, a navigation system for VPS is necessary to decrease these complication rates.

Although previous studies[10, 12] have reported that compared with conventional surgery the use of a navigation system in VPS achieves superior results, the relationships among clinical symptoms, ventricular catheter placement, catheter obstruction and the postoperative Evans index have not been clearly reported. In this study, we review patients with hydrocephalus who underwent intraoperative navigation surgery to evaluate the possibility that the accuracy of proximal catheter placement is improved by a navigation system in VPS and explore the probable relationships among ventricular catheter obstruction, the symptom grade and the postoperative Evans index. 


\section{Methods}

\section{Demographic data}

This study retrospectively reviewed a series of 59 patients with hydrocephalus who underwent VPS at the neurosurgery department of the Affiliated Hospital of Yangzhou University, Jiangsu, China, between January 2012 and August 2018. Thirty-three patients were included in the navigation surgery group, and 26 patients were included in the conventional surgery group, in which surgeons were limited to taking advantage of cranial anatomical landmarks. When allocating patients to groups, we considered factors including (1) the patient's condition, such as the history of frontal-temporal decompression craniectomy; (2) the morphological characteristics of the ventricle, including the size of the ventricle and the presence or absence of displacement; and (3) the neurosurgeon's preference.

The inclusion criteria for surgery were as follows: (1) The patient exhibited clinical symptoms, including gait disturbance, cognitive impairment or urinary incontinence; (2) The imaging examinations demonstrated that the ventricle was enlarged and showed edema along its wall; (3) A lumbar puncture (LP) tap test was positive; (4) The characteristics of CSF were normal. Patients with previous shunt failures caused by dysfunction or distal failure, those with obstructive hydrocephalus, and those who had previously undergone neuroendoscopic surgery were excluded.

All patients were evaluated at admission for symptom severity according to symptom grading[13] criteria and underwent thin-slice CT (Siemens, Germany) or MRI (Siemens, 3.0T) examinations (scans ranged from the upper lip, including the apex nasi region, to the parietal region; slice thickness: $1 \mathrm{~mm}$ ) before surgery. LP was performed in all patients using the tap test to measure intracranial pressure (ICP) and CSF parameters, including the protein concentration and red blood cell counts. VPS equipment, including a ventricular catheter, a peritoneal catheter and a programmable antisiphon valve (Strata $\otimes$ Valve, Regular, Medtronic, USA), was used.

\section{Preoperative planning and operative procedure}

In the navigation surgery group, imaging data obtained in preoperative CT or MR scans of patients were stored on CD-ROMs and uploaded from there into the navigation system (StealthStation S7 Fusion, Medtronic, USA). Then, the target point, entry point, trajectory and depth of insertion were preoperatively planned using the navigation software (Fig. 1). The navigation reference antenna was fixed to a Mayfield holder that was used to fix the patient's head. After successful registration via the trace approach, calibration according to maxillofacial surface landmarks was performed to examine the accuracy error, and the accuracy error was controlled to within $2 \mathrm{~mm}$. Navigation was then performed in advance to find the entry point according to the preoperative routine. Furthermore, the entry point was verified again via intraoperative navigation before a portion of the skull was removed with a milling cutter (Medtronic, USA). After the dura was cut, the ventricle catheter with the navigation tracker was adjusted to the expected position in accordance with preoperative planning for connection to the programmable valve. Next, a 4- to 5-cm middle incision in the upper abdomen was made to divide the subcutaneous tissue, and the sheath of the rectus abdominis and the peritoneum was cut to access the peritoneal cavity. Before the peritoneal catheter was placed in the superior region of the liver, the CSF flow was confirmed with smoothing from the proximal catheter tip.

In the conventional group, Frazier's point on the right side was usually selected as the entry point. The insertion length was generally 8-10 cm through the occipital horn. The rest of the operative procedure was the same as that described for the navigation group. All operations were performed by senior neurosurgeons.

Page $3 / 20$ 


\section{Outcome measurements}

In the present study, the severity of symptoms were evaluated according to a grading system[13] before (at admission) and after surgery (at 6 months after surgery). The etiology of hydrocephalus, CSF parameters, catheterization accuracy, operation time, complications, follow-up time and catheter obstruction-free survival time after surgery were also evaluated. Ventricular catheter placement was also assessed based on a grading system[12]. The correlation between ventricular catheter placement and catheter obstruction was analyzed as were the correlations between catheter obstruction and the symptom grade and postoperative Evans index. All patients underwent CT scans on the $1^{\text {st }}$ day after surgery to determine the position of the ventricular catheter and to rule out bleeding. The first follow-up was performed within 1 month of discharge, and subsequent follow-ups were performed within 3, 6, 12, 24 and 48 months. The follow-up evaluations included the patient's symptoms and imaging examinations according to the variation in the patient's symptoms.

\section{Statistical analysis}

Statistical analyses were performed using SPSS v.23.0 (Armonk, New York, United States). Independent t tests were used to compare continuous variables, which are expressed as the mean \pm standard deviation. In the navigation surgery group, differences in the depth and grade of ventricular catheter placement were analyzed between the preoperative plan and postoperative results by paired t test. Categorical variables in these 2 groups were compared by the Mann-Whitney test. The correlations between catheter obstruction and the postoperative Evans index and symptom grade as well as the relationship between proximal catheter placement and catheter obstruction were evaluated by Pearson correlation analysis. Cumulative catheter obstruction-free survival was calculated by KaplanMeier survival statistics.

\section{Results}

\section{Comparison of clinical characteristics in the navigation and conventional surgery groups}

The mean age of the patients in the navigation surgery group was 56.18 years old (range, 21 to 78 years), while the mean age of the patients in the conventional surgery group was 58.73 years old (range, 23 to 73 years). In this study, the most common causes of hydrocephalus in the navigation surgery group were cerebrovascular diseases (48.48\%) followed by head trauma (27.27\%), and these were also the most common causes of hydrocephalus in the conventional surgery group, in which they affected $46.15 \%$ and $38.46 \%$ of the patients, respectively (Table 2 ). No significant differences were observed between these 2 groups in the preoperative findings, including in the preoperative Evans index and CSF characteristics (Table 2).

\section{Accuracy and precision of ventricular catheterization in the navigation surgery group}

For the preoperative plans used in the navigation group, the mean depth of the ventricular catheter and the grade of catheter placement determined by the navigation system were not significantly different from those determined based on postoperative CT (Table 3). 


\section{Postoperative outcomes of the 2 groups}

In the navigation surgery group, in contrast with the preoperative symptoms, the postsurgical symptoms observed after VPS (Table 4) were significantly better $(\mathrm{P}<0.001)$ at six months after surgery, whereas no significant difference was seen in the conventional surgery group $(P=0.096)$. In addition, at six months after surgery, the clinical symptoms were substantially better in the navigation group than in the conventional surgery group $(\mathrm{P}=0.017)$. During preoperative planning (Fig. 1), postoperative CT was used to determine the optimal ventricular catheter placement for the VPS (Fig. 2). The total number of patients in whom each grade of ventricular catheter placement was used in the 2 groups is presented in Fig. 3.

Nine patients (34.62\%) in the conventional surgery group and 3 patients (9.09\%) in the navigation surgery group developed ventricular catheter obstruction $(P<0.001$, Table 5). According to the correlation analysis, catheter obstruction was significantly correlated with symptom grade and the postoperative Evans index (Fig. 4). In addition, ventricular catheter placement was significantly correlated with catheter obstruction $(P<0.001$, Table 6). The detailed characteristics of the cases in which ventricular catheter obstruction occurred are described in Table 7.

Additionally, the average total operative time (from skin incision to skin closure) was 64.00 minutes (range, 55-75 minutes) in the navigation surgery group and 77.77 minutes (range, 65-89 minutes) in the conventional surgery group $(\mathrm{P}<0.001)$. The postoperative Evans index and the rate of ventricular catheter obstruction were also significantly different between the two groups $(P<0.001)$, although the incidences of postoperative infection $(P=0.264)$ and bleeding $(P=0.264)$ were not significantly different between the groups (Table 5).

\section{Catheter obstruction-free survival after VPS}

The mean follow-up time was 19.15 months (range, 1-36 months) in the navigation surgery group and 18.46 months (range, 1-38 months) in the conventional surgery group (Fig. 5), and these times were not significantly different $(P=0.760$, Table 5). Furthermore, the Kaplan-Meier survival analysis of post-VPS catheter obstruction-free survival within the follow-up time period is presented in Fig. 6. The Kaplan-Meier survival analysis indicated that the cumulative catheter obstruction-free survival time was longer in the navigation surgery group than in the conventional surgery group. The initial slope was much steeper in the conventional surgery group than in the navigation surgery group, which indicates that catheter obstruction occurred earlier in the conventional surgery group $(P=0.028$, Table 8).

\section{Discussion}

In this report, we demonstrate that performing VPS for hydrocephalus via the occipital horn with a navigation system is superior to the conventional surgical procedure in terms of clinical outcomes, the accuracy and precision of ventricular catheterization, and occurrence of complications. We report the detailed characteristics of the cases that experienced ventricular catheter obstruction, and we found that catheter placement was significantly correlated with catheter obstruction. In addition, catheter obstruction was significantly correlated with symptom grade and postoperative Evans index. Finally, we also found that the cumulative catheter obstruction-free survival time was longer in the navigation surgery group than in the conventional surgery group.

Catheter placement into the lateral ventricle at a location remote from other structures is common in VPS, and accurate placement of the ventricular catheter is very important for long-term catheter obstruction-free survival. Accurate catheter placement may be more easily achieved when intraoperative navigation is used during VPS. 
Previous studies[11, 14-19] have reported the use of ultrasound, frameless stereotaxy, neuroendoscopy and navigation to increase the accuracy of ventricular catheter placement and improve long-term outcomes in patients with hydrocephalus. A systematic review by Flannery[20] showed that there was insufficient evidence to recommend the use of neuroendoscopy for routine VPS. Additionally, a meta-analysis by Nesvick et al.[16] revealed that ultrasound and stereotaxy did not increase catheter placement accuracy and provided only a weak benefit for patients with hydrocephalus. Yamada et al.[21] reported that 48 patients who underwent navigation surgery for VPS did not need shunt revision, but the effective rate was not reported due to loss of patients to follow-up. In this study, we report the results obtained over an approximately 36-month follow-up period in patients with hydrocephalus who underwent VPS with either intraoperative navigation or a conventional approach.

Conventional VPS, which is based only on cranial anatomic landmarks and personal experience, is a relatively easy procedure, although misplaced proximal catheters are associated with negative side effects and those patients may be at greater risk for eventual blockage, which makes another shunt revision necessary. Yoon et al.[11] found that $31.7 \%$ of patients with suboptimal catheter placement experienced catheter obstruction. Janson et al.[10] showed that when intraoperative fluoroscopic imaging was used, $43.9 \%$ of patients received optimal catheter placement, while $56.1 \%$ of patients received suboptimal or poor shunt placement and had a $57 \%$ higher risk of shunt failure.

In this study, in the conventional VPS group, 14 patients (53.84\%) had suboptimal catheter placement, and 6 patients (23.08\%) had poor placement mainly because the direction of ventricular catheterization was skewed. Ultimately, 9 (34.62\%) patients experienced ventricular catheter obstruction over a mean follow-up time of 18.46 months and subsequently required catheter readjustment. Moreover, all patients with grade 3 catheter placement experienced catheter obstruction during the first year after surgery; only one patient required 3 punctures (Table 7).

Intraoperative navigation for VPS has advantages, including high accuracy and the ability to perform reliable preoperative planning using navigational software. Intraoperative navigation can also increase the accuracy and precision of ventricular catheter placement. In this study, a programmable valve was selected for all patients, and the parameter of the programmable valve was initially set to 1.0-1.5 to avoid drainage based on the ICP obtained by LP. To determine the insertion trajectory during preoperative planning, the target point was required to be located far from the choroid plexus and the foramen. Additionally, in all cases, successful ventricular catheter insertion was achieved with an accurate target point, a reliable trajectory, and real-time monitoring. In the navigation group, only 2 patients (6.06\%) received suboptimal placement because too much CSF drained during the operation, which caused the brain to shift. Nimsky et al.[22] demonstrated that accuracy may be significantly compromised when brain shift occurs secondary to CSF drainage during surgery. However, the accuracy error was less than $2 \mathrm{~mm}$ according to a comparison of the depth of the inserted ventricular catheter on postoperative CT and the depth determined by the navigational software used during preoperative planning.

Although many neurosurgeons typically utilize the frontal horn approach and the occipital horn approach for VPS, the optimal surgical approach remains controversial[10]. Previous studies have reported[10,21, 23] that the success rate of the frontal approach via a freehand procedure ranges from 43.9-64\%. In addition, some studies[24, 25] have demonstrated that performing VPS via the frontal horn approach may increase the incidence of epilepsy in patients with hydrocephalus, especially among children. The catheter can be advanced via the occipital horn to reach the frontal horn far away from the choroid plexus. In addition, the occipital horn approach may be selected as the entry point in patients with hydrocephalus who undergo frontal-temporal decompression craniectomy regardless of how difficult it is to palpate the external occipital protuberance. All these factors make intraoperative navigation essential for an occipital approach in VPS. 
The efficacy of VPS has been extensively studied by evaluating multiple factors, which mainly include clinical symptoms and radiological outcomes. Karimy et al.[26] mentioned that the mechanism of posthemorrhagic hydrocephalus may involve CSF hypersecretion. Benveniste et al.[27] reported that $80 \%$ of patients showed objective improvement in hydrocephalus symptoms after VPS, although $49 \%$ of patients developed delayed deterioration of symptoms, most likely due to shunt failure or underdrainage. In this study, in the navigation surgery group, the clinical symptoms of most patients substantially improved after VPS. Additionally, we found that ventricular catheter obstruction was significantly correlated with symptom grade $(P=0.001)$ and the postoperative Evans index $(P<0.001$, Fig. 4). A probable explanation may be that sufficient CSF drainage, when combined with accurate catheter placement, results in symptomatic improvements and decreased ventricular size. However, due to attrition during clinical follow-up, a larger population with appropriate follow-up durations may be necessary to determine the effectiveness of VPS.

Whether the use of navigation increases operation times remains controversial. Although installation and registration require time, an experienced user can complete all these operations quickly while intravenous anesthesia is administered. Additionally, previous studies[12, 28] have demonstrated that the additional time spent preparing for navigation did not exceed 15 minutes. Therefore, the extra time needed would not increase the overall procedure time. In this study, the operation time (from skin incision to skin closure) was shorter in the navigation surgery group than in the conventional surgery group because skilled neurosurgeons performed the procedures based on the individualized design of surgical approaches obtained using the navigation system.

The most common complications of VPS are infection and shunt failure, which lead to many hospital readmissions. In a review by Paf et al.[29], the infection rate was approximately 8-15\% among patients who underwent VPS placement. In this study, no infections were observed among the patients in the navigation group, and only one patient (3.85\%) in the conventional group who underwent 3 punctures during the operation developed an infection. Hayhurst[12] showed that $78 \%$ of standard shunts fail during the early stage, mainly due to proximal obstruction. Deckerman et al.[30] demonstrated that catheters placed farther from the choroid plexus were correlated with a lower rate of shunt failure at six months. In this study, 3 patients $(9.09 \%)$ in the navigation surgery group developed catheter obstruction, while $34.62 \%$ of patients in the conventional surgery group developed catheter obstruction. In one case in which the occipital approach was used in the conventional surgery group, due to location inaccuracy, the burr hole was made too close to the midline and caused slight damage to the superior sagittal sinus and a subsequent subdural hematoma.

A study presented by Jeremiah et al.[6] showed that according to a Kaplan-Meier survival analysis, a poor catheter position was substantially more likely to require subsequent shunt revision. Reddy[9] demonstrated that adult patients had significantly higher revision-free survival times than pediatric patients after their first shunt surgery and that most shunt revisions occurred early (within six months). In this study, catheter obstruction-free survival times were longer in the navigation surgery group than in the conventional surgery group $(P=0.028)$. A Kaplan-Meier survival curve (Fig. 6) presumably indicated that catheter obstruction-free survival was related to intraoperative navigation during VPS. The initial slope was much steeper for the conventional surgery group than for the navigation surgery group, which demonstrates that catheter obstruction occurred earlier in the conventional surgery group.

This study has certain limitations. First, this was a nonrandomized, single-center retrospective study of a small number of cases that did not include pediatric patients with hydrocephalus because only a few pediatric patients with hydrocephalus underwent VPS, and some of these patients had a negative CSF tap test or inadequate follow-up data. In addition, this study included only patients who underwent catheter insertion via the occipital horn; therefore, the possibility of selection bias due to this methodology cannot be ignored. Second, we did not have a way to 
randomize the choice of navigation for VPS. Third, the sample size was too small to perform a multivariate analysis of all risk factors to predict the prognosis of patients with hydrocephalus and long-term catheter obstruction-free survival, and this should be further evaluated in a randomized controlled clinical trial. Therefore, a multicenter, prospective clinical trial based on a large population with appropriate follow-up durations may be necessary to determine the effectiveness of VPS, which could provide clear benefits to patients with hydrocephalus.

\section{Conclusions}

Our findings suggest that the use of intraoperative navigation in VPS resulted in accurate and precise proximal catheter placement and improved symptoms in patients with hydrocephalus. We found that catheter obstruction was significantly correlated with symptom grade and the postoperative Evans index. Additionally, ventricular catheter placement was significantly correlated with catheter obstruction and the longevity of catheter obstruction-free survival, which were better in the navigation surgery group than in the conventional surgery group.

\section{Abbreviations}

CSF: Cerebrospinal fluid; CT: Computed tomography; iNPH: Idiopathic normal pressure hydrocephalus; ICP: Intracranial pressure; LP: Lumbar puncture; MRI: Magnetic resonance imaging; NPH: Normal pressure hydrocephalus; VPS: Ventriculoperitoneal shunting.

\section{Declarations}

\section{Ethics approval and consent to participate}

This study was approved by the ethics committee of West China Hospital, Sichuan University, China. Informed consent was obtained from all individual participants included in the study.

\section{Consent for publication}

The patient's family has consented to use of images and the submission of the article for publication in a journal.

\section{Availability of data and material}

The datasets generated and analyzed during the current study are not publicly available since identifiable patient data should not be shared, but they may be available from the corresponding author upon reasonable request.

\section{Competing interests}

The authors declare no conflicts of interest.

\section{Funding}

This study was funded by Sichuan Provincial Human Resources and the Social Security Department (Grant Number 0040205301G04); these funding agencies had no role in the collection, analysis and interpretation of data or in writing the manuscript. 


\section{Authors' contributions}

P AJ, W YK and Z Y were involved in the study design and data collection. The manuscript was written by P AJ. P AJ and $\mathrm{Z} \mathrm{H}$ were responsible for the statistical analyses and interpretation of study results. Z LX served as principal investigator for the study, contributed data and participated in data interpretation as well as in the development of the manuscript. All authors have made substantial contributions to this study and approved submission to this journal.

\section{Acknowledgements}

We thank the staff of the Neurosurgery department at the Affiliated Hospital of Yangzhou University, who generously assisted with the VPS in this study.

\section{References}

1. Dewan MC, Rattani A, Mekary R, Glancz LJ, Yunusa I, Baticulon RE, et al. Global hydrocephalus epidemiology and incidence: systematic review and meta-analysis. Journal of neurosurgery. 2018:1-15; doi:

10.3171/2017.10.JNS17439.

2. Brean A, Eide PK. Prevalence of probable idiopathic normal pressure hydrocephalus in a Norwegian population. Acta Neurol Scand. 2008;118 1:48-53; doi: 10.1111/j.1600-0404.2007.00982.x.

3. Mori E, Ishikawa M, Kato T, Kazui H, Miyake H, Miyajima M, et al. Guidelines for management of idiopathic normal pressure hydrocephalus: second edition. Neurol Med Chir (Tokyo). 2012;52 11:775-809.

4. Simon TD, Riva-Cambrin J, Srivastava R, Bratton SL, Dean JM, Kestle JR, et al. Hospital care for children with hydrocephalus in the United States: utilization, charges, comorbidities, and deaths. J Neurosurg Pediatr. 2008;1 2:131-7; doi: 10.3171/PED/2008/1/2/131.

5. Patwardhan RV, Nanda A. Implanted ventricular shunts in the United States: the billion-dollar-a-year cost of hydrocephalus treatment. Neurosurgery. 2005;56 1:139-44; discussion 44-5.

6. Jeremiah KJ, Cherry CL, Wan KR, Toy JA, Wolfe R, Danks RA. Choice of valve type and poor ventricular catheter placement: Modifiable factors associated with ventriculoperitoneal shunt failure. Journal of clinical neuroscience : official journal of the Neurosurgical Society of Australasia. 2016;27:95-8; doi: 10.1016/j.jocn.2015.07.026.

7. Gilard V, Magne N, Gerardin E, Curey S, Pelletier V, Hannequin P, et al. Comparison of electromagnetic neuronavigation system and free-hand method for ventricular catheter placement in internal shunt. Clinical neurology and neurosurgery. 2017;158:93-7; doi: 10.1016/j.clineuro.2017.05.007.

8. Wan KR, Toy JA, Wolfe R, Danks A. Factors affecting the accuracy of ventricular catheter placement. Journal of clinical neuroscience : official journal of the Neurosurgical Society of Australasia. 2011;18 4:485-8; doi:

10.1016/j.jocn.2010.06.018.

9. Reddy GK, Bollam P, Caldito G. Long-term outcomes of ventriculoperitoneal shunt surgery in patients with hydrocephalus. World neurosurgery. 2014;81 2:404-10; doi: 10.1016/j.wneu.2013.01.096.

10. Janson CG, Romanova LG, Rudser KD, Haines SJ. Improvement in clinical outcomes following optimal targeting of brain ventricular catheters with intraoperative imaging. Journal of neurosurgery. 2014;120 3:684-96; doi: 
10.3171/2013.8.JNS13250.

11. Yoon SY, Kwak Y, Park J. Adjustable Ghajar Guide Technique for Accurate Placement of Ventricular Catheters: A Pilot Study. J Korean Neurosurg Soc. 2017;60 5:604-9; doi: 10.3340/jkns.2016.1011.004.

12. Hayhurst C, Beems T, Jenkinson MD, Byrne P, Clark S, Kandasamy J, et al. Effect of electromagnetic-navigated shunt placement on failure rates: a prospective multicenter study Clinical article. Journal of neurosurgery. 2010;113 6:1273-8; doi: 10.3171/2010.3.Jns091237.

13. Krauss JK, Droste DW, Vach W, Regel JP, Orszagh M, Borremans JJ, et al. Cerebrospinal fluid shunting in idiopathic normal-pressure hydrocephalus of the elderly: effect of periventricular and deep white matter lesions. Neurosurgery. 1996;39 2:292-9; discussion 9-300.

14. Crowley RW, Dumont AS, Asthagiri AR, Torner JC, Medel R, Jane JA, Jr., et al. Intraoperative ultrasound guidance for the placement of permanent ventricular cerebrospinal fluid shunt catheters: a single-center historical cohort study. World neurosurgery. 2014;81 2:397-403; doi: 10.1016/j.wneu.2013.01.039.

15. Reig AS, Stevenson CB, Tulipan NB. CT-based, fiducial-free frameless stereotaxy for difficult ventriculoperitoneal shunt insertion: experience in 26 consecutive patients. Stereotactic and functional neurosurgery. 2010;88 2:75-80; doi: $10.1159 / 000271822$.

16. Nesvick CL, Khan NR, Mehta GU, Klimo P, Jr. Image Guidance in Ventricular Cerebrospinal Fluid Shunt Catheter Placement: A Systematic Review and Meta-Analysis. Neurosurgery. 2015;77 3:321-31; discussion 31; doi: 10.1227/NEU.0000000000000849.

17. Yim B, Reid Gooch M, Dalfino JC, Adamo MA, Kenning TJ. Optimizing ventriculoperitoneal shunt placement in the treatment of idiopathic intracranial hypertension: an analysis of neuroendoscopy, frameless stereotaxy, and intraoperative CT. Neurosurgical focus. 2016;40 3:E12; doi: 10.3171/2015.12.FOCUS15583.

18. Peraio S, Amen MM, Ali NM, Zaher A, Mohamed Taha AN, Tamburrini G. Endoscopic Management of Pediatric Complex Hydrocephalus. World neurosurgery. 2018; doi: 10.1016/j.wneu.2018.07.187.

19. Deopujari CE, Padayachy L, Azmi A, Figaji A, Samantray SK. Neuroendoscopy for post-infective hydrocephalus in children. Child's nervous system : ChNS : official journal of the International Society for Pediatric Neurosurgery. 2018;34 10:1905-14; doi: 10.1007/s00381-018-3901-z.

20. Flannery AM, Duhaime AC, Tamber MS, Kemp J. Pediatric hydrocephalus: systematic literature review and evidence-based guidelines. Part 3: Endoscopic computer-assisted electromagnetic navigation and ultrasonography as technical adjuvants for shunt placement. J Neurosurg-Pediatr. 2014;14:24-9; doi: 10.3171/2014.7.Peds14323.

21. Yamada S, Ishikawa M, Yamamoto K. Utility of Preoperative Simulation for Ventricular Catheter Placement via a Parieto-Occipital Approach in Normal-Pressure Hydrocephalus. Operative neurosurgery. 2018; doi:

10.1093/ons/opy193.

22. Nimsky C, Ganslandt O, Cerny S, Hastreiter P, Greiner G, Fahlbusch R. Quantification of, visualization of, and compensation for brain shift using intraoperative magnetic resonance imaging. Neurosurgery. 2000;47 5:1070-9; discussion 9-80. 
23. Wilson TJ, Stetler WR, Al-Holou WN, Sullivan SE. Comparison of the accuracy of ventricular catheter placement using freehand placement, ultrasonic guidance, and stereotactic neuronavigation Clinical article. Journal of neurosurgery. 2013;119 1:66-70; doi: 10.3171/2012.11.Jns111384.

24. Sato O, Yamguchi T, Kittaka M, Toyama H. Hydrocephalus and epilepsy. Child's nervous system : ChNS : official journal of the International Society for Pediatric Neurosurgery. 2001;17 1-2:76-86.

25. Larsson J, Israelsson H, Eklund A, Malm J. Epilepsy, headache, and abdominal pain after shunt surgery for idiopathic normal pressure hydrocephalus: the INPH-CRasH study. Journal of neurosurgery. 2018;128 6:1674-83; doi: 10.3171/2017.3.JNS162453.

26. Karimy JK, Zhang J, Kurland DB, Theriault BC, Duran D, Stokum JA, et al. Inflammation-dependent cerebrospinal fluid hypersecretion by the choroid plexus epithelium in posthemorrhagic hydrocephalus. Nature medicine. 2017;23 8:997-1003; doi: 10.1038/nm.4361.

27. Benveniste RJ, Sur S. Delayed symptom progression after ventriculoperitoneal shunt placement for normal pressure hydrocephalus. Journal of the neurological sciences. 2018;393:105-9; doi: 10.1016/j.jns.2018.08.002.

28. Stieglitz LH, Giordano M, Samii M, Luedemann WO. A New Tool for Frameless Stereotactic Placement of Ventricular Catheters. Neurosurgery. 2010;67 3:131-5; doi: 10.1227/01.Neu.0000382964.72262.9a.

29. Paff M, Alexandru-Abrams D, Muhonen M, Loudon W. Ventriculoperitoneal shunt complications: A review. Interdisciplinary Neurosurgery. 2018;13:66-70; doi: 10.1016/j.inat.2018.04.004.

30. Dickerman RD, McConathy WJ, Morgan J, Stevens QE, Jolley JT, Schneider S, et al. Failure rate of frontal versus parietal approaches for proximal catheter placement in ventriculoperitoneal shunts: revisited. Journal of clinical neuroscience : official journal of the Neurosurgical Society of Australasia. 2005;12 7:781-3; doi: 10.1016/j.jocn.2004.12.005.

\section{Tables}

Table 1 Outcome evaluation system 


\section{Outcome evaluation system}

\section{Grading system for the}

severity of hydrocephalus symptoms

\begin{tabular}{llll}
\hline Grade & Gait disturbance & Urinary incontinence & Cognitive impairment \\
\hline 0 & Normal & Normal & Normal \\
\hline 1 & $\begin{array}{l}\text { Cautious gait or impaired } \\
\text { tandem gait }\end{array}$ & $\begin{array}{l}\text { Sporadic } \\
\text { incontinence or urge } \\
\text { phenomenon }\end{array}$ & $\begin{array}{l}\text { Minimal attentional or } \\
\text { memory deficits }\end{array}$ \\
\hline 2 & Considerable unstable gait & $\begin{array}{l}\text { Frequent } \\
\text { incontinence }\end{array}$ & $\begin{array}{l}\text { Considerable deficits, but } \\
\text { oriented to situational } \\
\text { context }\end{array}$ \\
\hline 3 & Unaided gait not possible & $\begin{array}{l}\text { No or only minimal } \\
\text { control }\end{array}$ & $\begin{array}{l}\text { Not or only marginally } \\
\text { oriented }\end{array}$
\end{tabular}

\section{Grading system for placement of the ventricular catheter}

\section{Grade}

\section{1}

Optimal position free-floating

in CSF

2

Touching choroid or ventricular wall or not in the target ventricle

3

Catheter tip terminates in parenchyma

CSF: cerebrospinal fluid

Table 2 Comparison of the clinical data between the navigation and conventional surgery groups 


\begin{tabular}{llll} 
Variables & $\begin{array}{l}\text { Navigation surgery group } \\
(\mathbf{n = 3 3})\end{array}$ & $\begin{array}{l}\text { Conventional surgery } \\
\text { group } \\
(\mathbf{n}=26)\end{array}$ & $\begin{array}{l}\text { P- } \\
\text { value }\end{array}$ \\
\hline Age $(\mathrm{M} \pm \mathrm{SD})$ & $56.18 \pm 14.42$ & $58.73 \pm 13.74$ & 0.494 \\
\hline Gender, $\mathrm{N}(\%)$ & & $15(57.69)$ & \\
\hline Male & $19(57.58)$ & $11(42.31)$ & 0.993 \\
\hline Female & $14(42.42)$ & & \\
\hline Etiology, N (\%) & & $12(46.15)$ & \\
\hline Cerebrovascular diseases & $16(48.48)$ & $10(38.46)$ & \\
\hline Head trauma & $9(27.27)$ & $2(7.69)$ & 0.126 \\
\hline iNPH & $5(15.15)$ & $2(7.69)$ & 0.809 \\
\hline Brain tumors & $3(9.09)$ & $0.35 \pm 0.02$ & 0.439 \\
\hline Preoperative Evans Index $(\mathrm{M} \pm S D)$ & $0.34 \pm 0.02$ & $493.65 \pm 84.11$ \\
\hline Protein concentration in CSF (mg/L) & $464.70 \pm 82.80$ & $35.62 \pm 3.78$ \\
\hline $\begin{array}{l}\text { The total amount of CSF in tap test } \\
\text { (ml) }\end{array}$ & $36.42 \pm 4.09$ & & \\
\hline
\end{tabular}

$\mathrm{M} \pm S \mathrm{D}$ : mean \pm standard deviation, iNPH: idiopathic normal pressure hydrocephalus

Table 3 Evaluation of the depth and placement of the ventricular catheter in the navigation group

The accuracy of ventricular catheter

Pvalue

$\begin{array}{ll}\text { Preoperative planning } & \begin{array}{l}\text { After } \\ \text { surgery }\end{array}\end{array}$

The depth of ventricular catheter via the occipital horn $(\mathrm{cm})$

$9.18 \pm 0.34$

$9.32 \pm 0.36$

0.231

The grade of catheter placement

0.162

\begin{tabular}{lll}
\hline 1 & 33 & 31 \\
\hline 2 & 0 & 2 \\
\hline 3 & 0 & 0
\end{tabular}

Table 4 Comparison of the preoperative and postoperative symptom grade in each group 


\begin{tabular}{|c|c|c|c|c|c|c|c|c|c|}
\hline & $\begin{array}{l}\text { Navigation } \\
\text { surgery } \\
\text { group } \\
(n=33)\end{array}$ & & & & $\begin{array}{l}\text { Conventional } \\
\text { surgery } \\
\text { group } \\
(n=26)\end{array}$ & & & & $\begin{array}{l}\mathrm{P} \text { - } \\
\text { value }\end{array}$ \\
\hline $\begin{array}{l}\text { Symptom } \\
\text { grade }\end{array}$ & 0 & 1 & 2 & 3 & 0 & 1 & 2 & 3 & \\
\hline $\begin{array}{l}\text { Before } \\
\text { surgery } \\
N(\%)\end{array}$ & 0 & $\begin{array}{l}4 \\
(12.12)\end{array}$ & $\begin{array}{l}24 \\
(72.73)\end{array}$ & $\begin{array}{l}5 \\
(15.15)\end{array}$ & 0 & $\begin{array}{l}3 \\
(11.54)\end{array}$ & $\begin{array}{l}20 \\
(76.92)\end{array}$ & $\begin{array}{l}3 \\
(11.54)\end{array}$ & 0.818 \\
\hline $\begin{array}{l}\text { After } \\
\text { surgery } \\
N(\%)\end{array}$ & $\begin{array}{l}4 \\
(12.12)\end{array}$ & $\begin{array}{l}18 \\
(54.55)\end{array}$ & $\begin{array}{l}8 \\
(24.24)\end{array}$ & $\begin{array}{l}3 \\
(9.09)\end{array}$ & $\begin{array}{l}1 \\
(3.85)\end{array}$ & $\begin{array}{l}8 \\
(30.77)\end{array}$ & $\begin{array}{l}12 \\
(46.15)\end{array}$ & $\begin{array}{l}5 \\
(19.23)\end{array}$ & 0.017 \\
\hline P-value & $<0.001$ & 0.096 & & & & & & & \\
\hline
\end{tabular}

Table 5 Postoperative outcome concerning VPS between the navigation and conventional surgery groups

\begin{tabular}{|c|c|c|c|}
\hline Variables & Navigation surgery group $(n=33)$ & $\begin{array}{l}\text { Conventional surgery group } \\
(n=26)\end{array}$ & P-value \\
\hline Operative time (min), (M $\pm S D)$ & $64.00 \pm 5.86$ & $77.77 \pm 7.38$ & $<0.001$ \\
\hline Postoperative Evans Index $(\mathrm{M} \pm \mathrm{SD})$ & $0.26 \pm 0.04$ & $0.29 \pm 0.03$ & $<0.001$ \\
\hline Blockage of the catheter, $\mathrm{N}(\%)$ & $3(9.09)$ & $9(34.62)$ & $<0.001$ \\
\hline Infection & 0 & 1 & 0.264 \\
\hline $\begin{array}{l}\text { Catheter adjusted, } \\
\mathrm{N}(\%)\end{array}$ & $3(9.09)$ & $9(34.62)$ & $<0.001$ \\
\hline Bleeding & 0 & 1 & 0.264 \\
\hline Follow-up time (months), $(\mathrm{M} \pm \mathrm{SD})$ & $19.15 \pm 8.41$ & $18.46 \pm 8.78$ & 0.760 \\
\hline
\end{tabular}

Table 6 Correlation analysis between catheter placement and catheter obstruction

\begin{tabular}{lll} 
Variables & Pearson Coefficients & P-value \\
\hline Catheter placement & 0.740 & $<0.001$ \\
Catheter obstruction & & \\
& &
\end{tabular}

Table 7 Detailed characteristics of the cases in which ventricular catheter obstruction occurred in the groups 


$\begin{array}{lllll}\text { Case } & \text { Gender } & \text { Age } & \text { Etiology } & \begin{array}{l}\text { Symptom } \\ \text { grade }\end{array}\end{array}$

\begin{tabular}{|c|c|c|c|c|c|c|c|}
\hline $\begin{array}{l}\text { Navigation } \\
\text { surgery group }\end{array}$ & & & & & & & \\
\hline 1 & $M$ & 68 & Head trauma & 2 & 2 & 1 & 26 \\
\hline 2 & $M$ & 61 & $\begin{array}{l}\text { Cerebrovascular } \\
\text { diseases }\end{array}$ & 3 & 1 & 1 & 35 \\
\hline 3 & $\mathrm{~F}$ & 53 & $\begin{array}{l}\text { Cerebrovascular } \\
\text { diseases }\end{array}$ & 3 & 2 & 1 & 32 \\
\hline $\begin{array}{l}\text { Conventional } \\
\text { surgery group }\end{array}$ & & & & & & & \\
\hline 1 & $\mathrm{~F}$ & 45 & Head trauma & 3 & 3 & 1 & 5 \\
\hline 2 & $\mathrm{M}$ & 73 & $\begin{array}{l}\text { Cerebrovascular } \\
\text { diseases }\end{array}$ & 3 & 2 & 1 & 18 \\
\hline 3 & $M$ & 68 & $\begin{array}{l}\text { Cerebrovascular } \\
\text { diseases }\end{array}$ & 3 & 2 & 1 & 17 \\
\hline 4 & $\mathrm{~F}$ & 57 & Head trauma & 2 & 1 & 1 & 22 \\
\hline 5 & $M$ & 72 & $\begin{array}{l}\text { Cerebrovascular } \\
\text { diseases }\end{array}$ & 2 & 3 & 1 & 4 \\
\hline 6 & $\mathrm{M}$ & 49 & Head trauma & 2 & 3 & 1 & 6 \\
\hline 7 & $\mathrm{~F}$ & 57 & $\begin{array}{l}\text { Cerebrovascular } \\
\text { diseases }\end{array}$ & 2 & 3 & 3 & 1 \\
\hline 8 & $\mathrm{M}$ & 61 & $\begin{array}{l}\text { Cerebrovascular } \\
\text { diseases }\end{array}$ & 2 & 3 & 1 & 8 \\
\hline 9 & $M$ & 54 & Head trauma & 2 & 3 & 2 & 9 \\
\hline
\end{tabular}

Table 8 Survival distribution between navigation and conventional surgery groups

Overall comparisons

\begin{tabular}{llll}
\hline & $\chi 2$ & Degree of freedom & P-value \\
\hline Log Rank(Mantel-Cox) & 4.828 & 1 & 0.028 \\
\hline Breslow(Generalized Wilcoxon) & 8.640 & 1 & 0.003 \\
\hline Tarone-Ware & 8.051 & 1 & 0.005
\end{tabular}

\section{Figures}




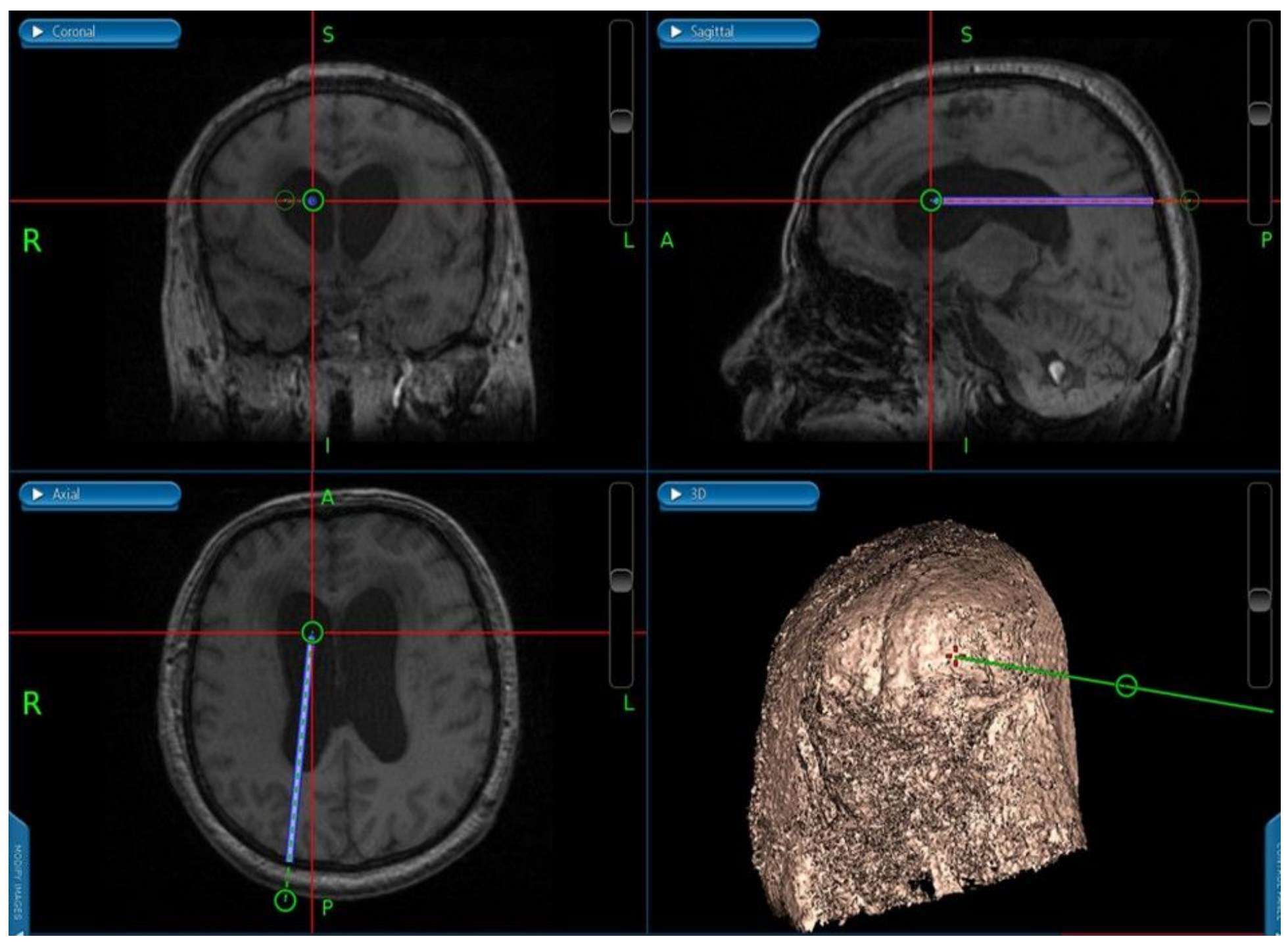

\section{Figure 1}

This was a preoparative planning picture for one patient with hydrocephalus in navigation system This was the coronal, sagittal, axial and 3D imaging. The green circle in ventricle was the target point, while another green circle in picture $c$ was the entry point. The blue line was trajectory. 


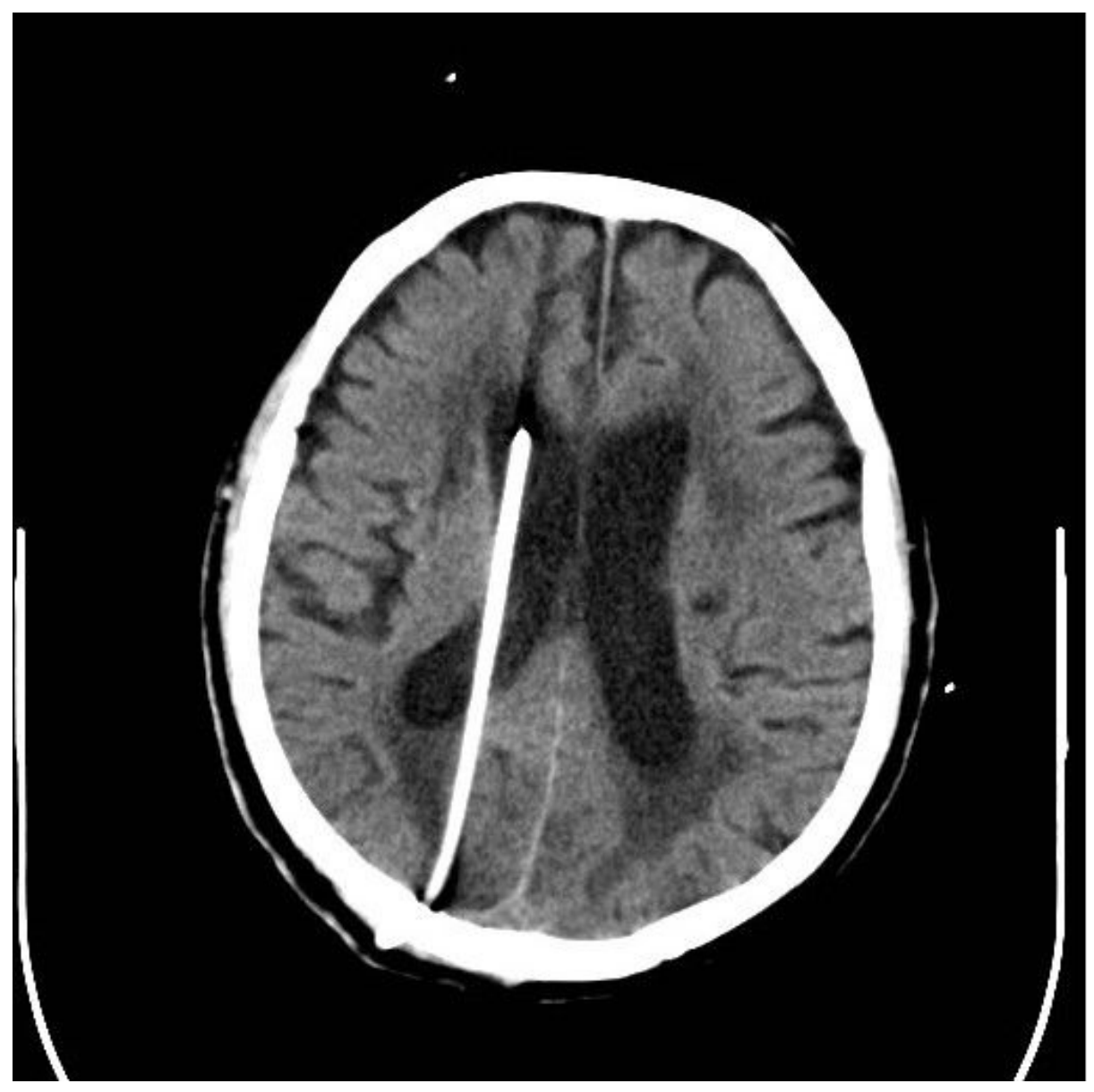

Figure 2

CT scan was for one patient with VPS during the 1st day after surgery It showed the ventricular catheter tip was in the target zone (grade 1). 


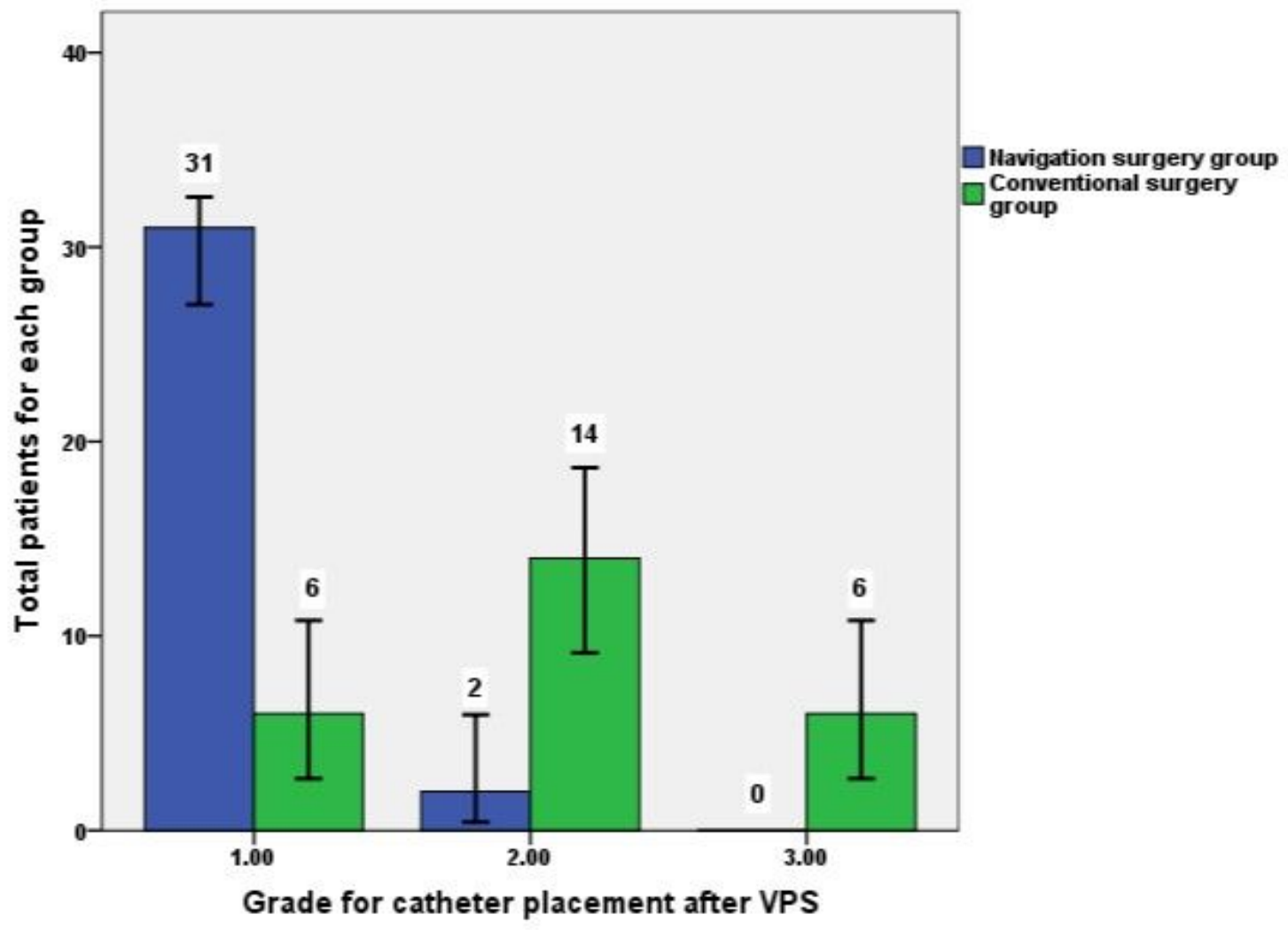

Figure 3

The total patients in each grade for catheter placement after VPS between these 2 groups.

\section{Postoperative Blockage of Symptom \\ Evans Index the catheter grade}

Postoperative

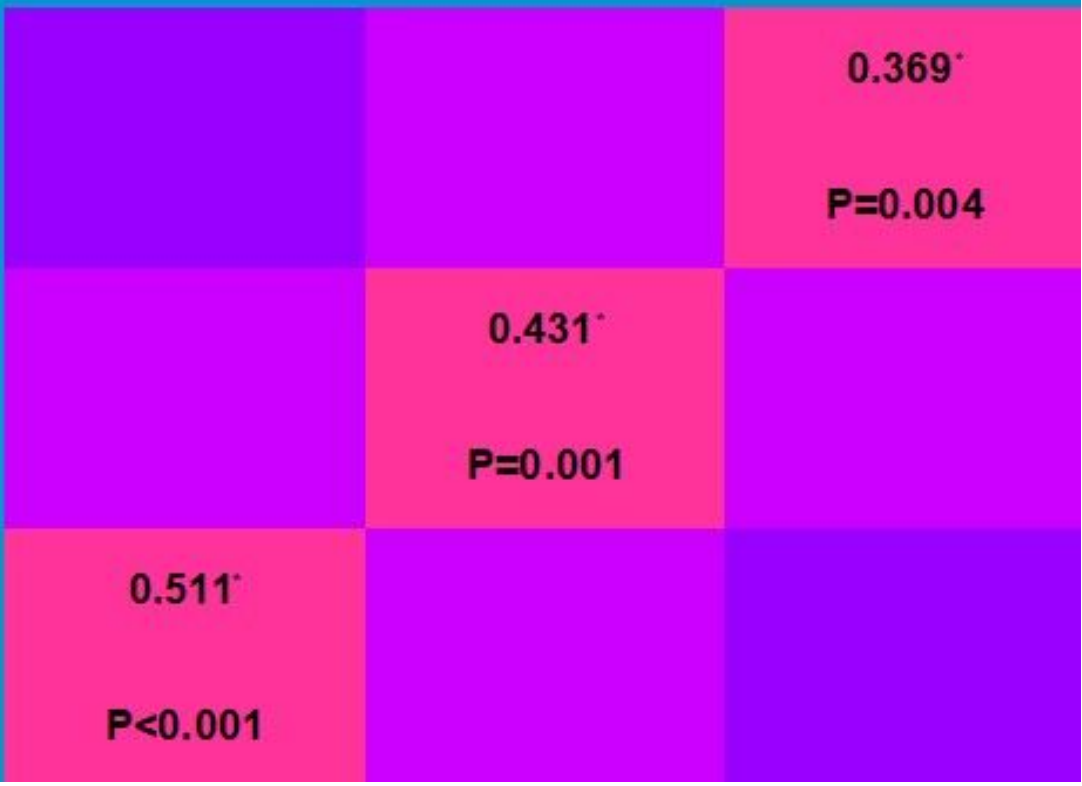

Evans Index

Symptom

grade

Blockage of

\section{$0.511^{*}$}

the catheter

\section{$P<0.001$}

\section{Figure 4}

The correlations of catheter obstruction with symptom grade and postoperative Evans index. *: Pearson coefficient 


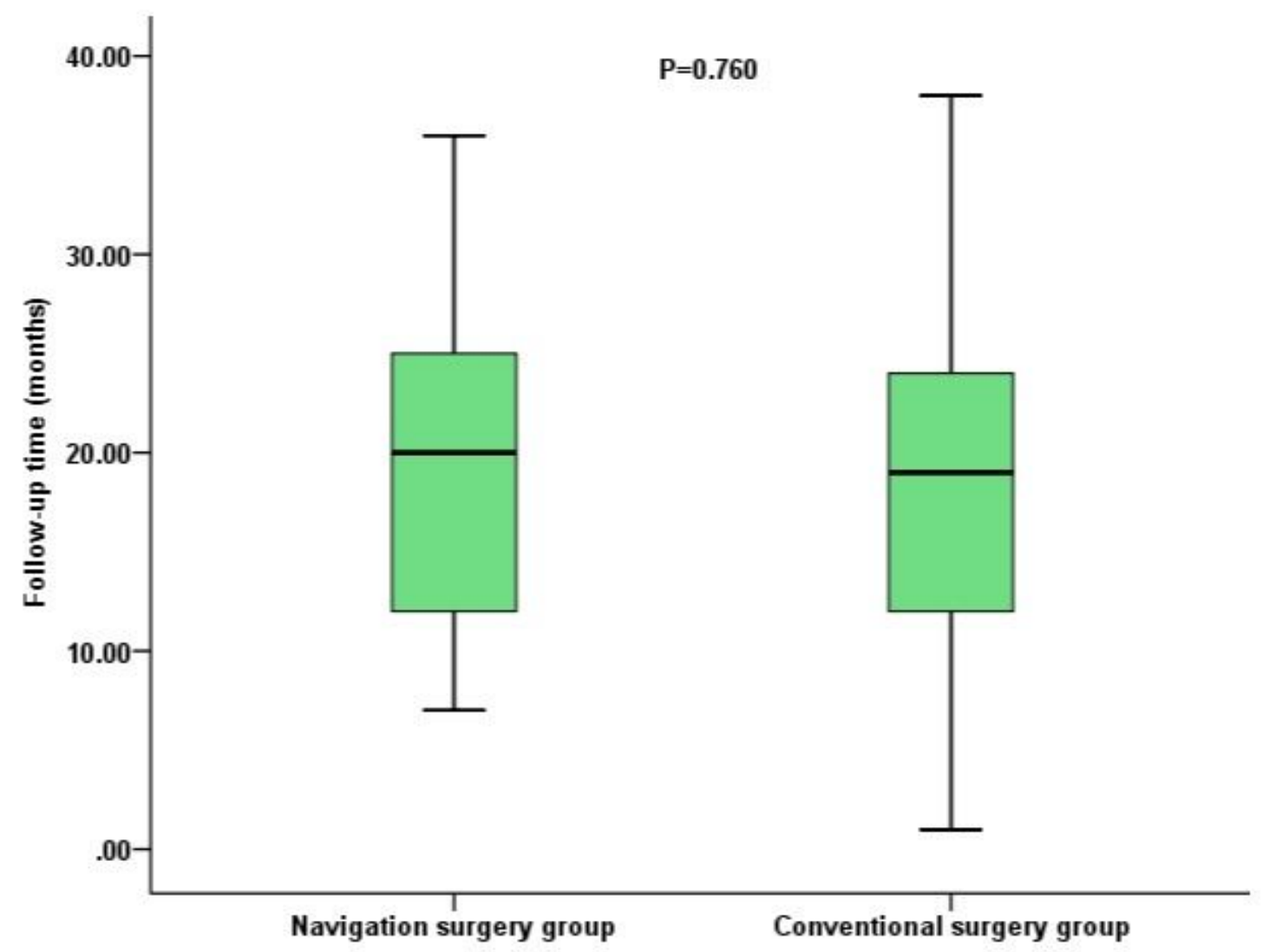

Figure 5

The Box-plot of follow-up time for these 2 groups.

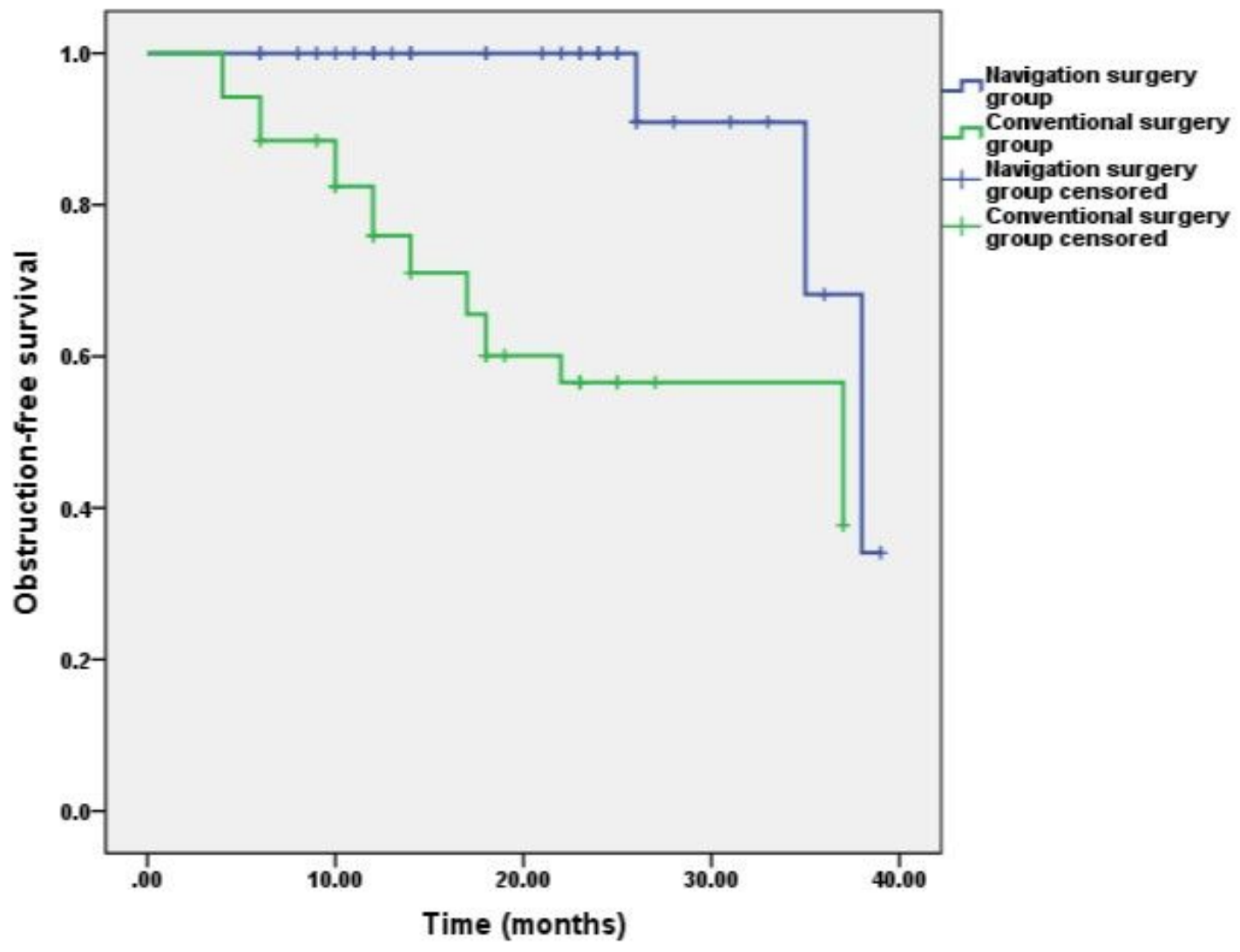

Page $19 / 20$ 


\section{Figure 6}

The Kaplan-Meier curve of the cumulative survival time between navigation and conventional surgery groups. A Kaplan-Meier survival curve presumably indicated that catheter obstruction-free survival was related to intraoperative navigation during VPS. The initial slope was much steeper for the conventional surgery group than for the navigation surgery group, demonstrating that catheter obstruction occurred earlier in the conventional surgery group. 